\title{
A Música de Hans Erdmann no Filme Nosferatu, Eine Symphonie des Grauens (Friedrich Murnau, 1922)
}

\author{
Anna Amorós-Pons \\ Departamento de Comunicación Audiovisual e Publicidade, \\ Facultade de Ciencias Sociais e da Comunicación, \\ Universidade de Vigo, Vigo, Espanha \\ https://orcid.org/0000-0002-2233-0102 \\ Nuria Gómez-Otero \\ Centro Musical LIRA-San Miguel de Oia, Vigo, Espanha \\ https://orcid.org/0000-0003-4046-3598
}

\begin{abstract}
Este artigo centra-se no estudo da banda sonora musical do compositor Hans Erdmann, feita para o filme alemão Nosferatu, Eine Symphonie des Grauens (Nosferatu, o Vampiro; 1922) pelo realizador Friedrich Murnau. A metodologia combina a técnica qualitativa do estudo de caso com abordagens recentes na análise musicológica de bandas sonoras de filmes. Esta investigação destaca os elementos estilísticos, recursos estruturais, influências musicais, referências de compositores e orquestração instrumental da partitura. A criação romântica de Erdmann é também influenciada pelo estilo barroco, classicismo e impressionismo. Este artigo constitui um novo contributo na área, uma vez que não foram encontrados estudos musicais ou cinematográficos com o tratamento aqui oferecido.
\end{abstract}

Palavras-chave: cinema, música, expressionismo alemão, Nosferatu, o Vampiro, Hans Erdmann

\section{Hans Erdmann's Music in the Film Nosferatu, Eine Symphonie des Grauens (Friedrich Murnau, 1922)}

The text focuses on the study of the musical soundtrack by the composer Hans Erdmann, made for the German film Nosferatu, Eine Symphonie des Grauens (Nosferatu, the Vampyre; 1922) by the director Friedrich Murnau. Its methodology combines the qualitative technique of case studies with the latest trends in the musicological analysis of film soundtracks. Research shows the stylistic elements, structural resources, musical influences, references to composers and the instruments used in this musical composition. The romantic creation by Erdmann also has influences of baroque style, classicism, and impressionism. It constitutes an innovative contribution in the area as musical and film studies of the nature that is presented in this contribution cannot be easily found.

Keywords: cinema, music, German expressionism, Nosferatu, the Vampyre, Hans Erdmann

Submetido: 25/10/2021 | Revisto: 29/11/2021 | Aceite: 29/11/2021 | Publicado: 21/12/2021

\section{Introdução}

Nosferatu, Eine Symphonie des Grauens (Nosferatu, o Vampiro; Friedrich Murnau, 1922) é ainda reconhecido, 100 anos mais tarde, como o filme mais representativo do género e do expressionismo alemão pelo seu valor narrativo-estético. Quando abordados a partir do género fantástico-terror e do tema do vampiro, os estudos sobre o cinema da época são vários. Contudo, as contribuições diminuem quando a investigação se centra na sua música, sendo também escassas quando o foco é o estudo da banda sonora e da partitura. Esta lacuna deve-se a circunstâncias estruturais, uma vez que estamos perante um filme sem banda sonora, estreado com música ao vivo, cuja partitura original se perdeu e foi posteriormente exibida com obras do elenco clássico; a deterioração do 
celuloide com o passar do tempo que levou a várias restaurações e, sobretudo, a preferência, na pesquisa audiovisual, pelo estudo da imagem em vez da banda sonora musical - circunstâncias que diminuíram as expectativas de abordar o seu estudo a partir da musicologia. Esta constitui uma contribuição oportuna, dado que nos aproximamos do centenário do filme.

\section{Quadro de Referência}

Embora existam precedentes na história do filme não sonoro sobre temas de vampiros (González, 2008; González Hevia, 2012; Peña Sevilla, 2000), é o filme de Friedrich Murnau que é realizado em pleno período expressionista alemão. Este filme não é apenas influenciado por este movimento, mas também recorre a outras referências culturais (Rubio, 2005) tais como o romantismo, Kammerspiel, a literatura de fantasia, o romance gótico e a pintura expressionista.

São várias as contribuições significativas sobre o trabalho de Friedrich Wilhelm Plumpe (conhecido como Friedrich Murnau) e Nosferatu, Eine Symphonie des Grauens, que proliferaram a partir de diferentes abordagens, destacando-se os estudos de Berriatúa (1990a, 1990b, 2001, 2009), Berriatúa e Pérez (1981), Bouvier e Leutrat (1981), Eisner (1964, 1955/1996), Jameux (1965), Kracauer (1947/1985), Patalas (2002), Sánchez-Biosca (1985, 1990) e Tone (1976). Contudo, quando abordada de uma perspetiva musicológica, a investigação é limitada, embora existam algumas obras notáveis que se centram na reconstrução da partitura original do filme (Gillian Anderson, s.d.; Heller, 1984; Müller \& Plebuch, 2012), no papel da música no cinema do período mudo (Altman, 2007; Anderson, 1988; Marks, 1997; Tieber \& Windisch, 2014), nas bandas sonoras em filmes expressionistas (Amorós \& Gómez, 2017, 2018) e compilações sobre música no cinema de terror (Hayward, 2009; Lerner, 2009); bem como estudos mais gerais, centrados nas funções da música no cinema (Colón et al., 1997; Navarro Arriola, 2005; Valls \& Padrol, 1986); no som e banda sonora no cinema (Chion, 1982, 1990/1993, 1995/1997); na transcendência dos compositores barrocos, clássicos e românticos nos usos da música cinematográfica (Lack, 1999); na funcionalidade rítmico-estética da banda sonora no filme (Nieto, 2003; Torelló, 2015); bem como abordagens mais conceptuais das nuances na análise de filmes musicais (Fraile, 2007; Lluis i Falcó, 1995); ou na utilização de música clássica com finalidade expressiva e/ou imitativa (Olarte, 2004, 2008).

Na estreia de Nosferatu, Eine Symphonie des Grauens (Berlim, 4 de março de 1922), teve lugar a única atuação ao vivo da banda sonora musical criada por Hans Erdmann (Berriatúa, 2009, p. 307), conduzida por O. Kernbach (Deutsche Kinemathek, 2003). A partitura original perdeu-se e durante algum tempo foi exposta com música de repertório clássico. Foram necessárias décadas para a reconstruir graças ao arquivo de documentos do período (García Merino, 2016, pp. 7-8; Navarro Arriola, 2005, p. 56), como o Fantastisch-romantische Suite (1926) de Erdmann, o compêndio de composições cinematográficas não sonoras Allgemeines Handbuch der Film-Musik (compilado por Erdmann, Becce e Brav em 1927) e a crítica musical na imprensa alemã da época.

Estudos recentes sobre esta banda sonora centram-se na reconstrução da partitura de Erdmann (García Merino, 2016, p. 8): com a obra do compositor Berndt Heller (1984), cuja proposta preserva os quarenta minutos originais de música, repetindo partes e acrescentando peças de repertório e adaptações de ópera; a contribuição de Gillian Anderson e James Kessler (Gillian Anderson, s.d.) que condensam a música em 40 minutos, incorporando repetições e material da sua autoria; e a proposta de Janina Müller e Tobias Plebuch (2013), criadores do termo "formas modulares", para encaixar diferentes fragmentos, variando instrumentos, dinâmicas, tempo, duração, carácter e função.

O estudo da composição de Hans Erdmann para Nosferatu, Eine Symphonie des Grauens de Friedrich Murnau, desperta interesse na investigação cinematográfica, devido à riqueza de nuances oferecidas pela partitura em sinergia com a imagem cinematográfica. 


\section{Materiais e Métodos}

O filme foi restaurado em várias ocasiões (Berriatúa, 2001). Há o filme a preto e branco, a versão sépia de Enno Patalas (Munique, 1984) e mais tarde foi feita outra de acordo com a coloração do período. A versão a cores (Friedrich Wilhelm Murnau Stiftung, 2005/2006) é feita com material da Filmoteca Espanhola, do Bundesarchiv-Filmarchiv (Berlim), da Cinemateca Francesa e de Bolonha e a colaboração de Luciano Berriatúa, especialista na sua obra (Berriatúa, 2009, pp. 275-313). Esta versão, com música original de Hans Erdmann e partitura reconstruída pelo austríaco Berndt Heller (1984), constitui o material utilizado neste trabalho (Table 1).

\begin{tabular}{|c|c|}
\hline Título & Nosferatu, Eine Symphonie des Grauens \\
\hline Título (Espanha) & Nosferatu, el Vampiro \\
\hline Ano & 1922 \\
\hline País & Alemanha \\
\hline Duração & 94 minutos \\
\hline Película & Branco e negro e tintas a cor \\
\hline Diretor & Friedrich W. Murnau \\
\hline Produção & Enrico Dieckmann, Albin Grau \\
\hline Produtora & Prana-Film \\
\hline Guião & Henrik Galeen \\
\hline Argumento & $\begin{array}{l}\text { Baseado no romance de Drácula (Bram Stoker, 1897), } \\
\text { adaptação livre }\end{array}$ \\
\hline Direção artística e design de vestuário & Albin Grau \\
\hline Fotografia & Fritz Arno Wagner, Günter Krampf (câmara) \\
\hline Género & Terror \\
\hline Estreia & 4 de março de 1922 \\
\hline Música & Hans Erdmann \\
\hline Diretor orquestra estreia & O. Kernbach \\
\hline Cidade estreia & Berlim (Salón Mármol, Jardim Zoológico) \\
\hline Contribuições e reconstrução musical & $\begin{array}{l}\text { Berndt Heller (1984), Gillian B. Anderson (1995), Janina } \\
\text { Müller e Tobias Plebuch (2013) }\end{array}$ \\
\hline Sinopse & $\begin{array}{l}\text { Um agente imobiliário (Jonathan Hutter) viaja para a } \\
\text { Transilvânia para fechar a compra de uma propriedade ao } \\
\text { Conde (Orlok) que é um vampiro (Nosferatu). Nas montanhas } \\
\text { dos Cárpatos, descobre alguns factos bastante invulgares. } \\
\text { Após a venda, regressa à sua cidade natal e Nosferatu segue- } \\
\text { o de barco, escondido em caixões com ratos, e instala-se na } \\
\text { sua nova casa, localizada em frente à casa do casal Hutter. } \\
\text { Uma poderosa atração fatal surge entre a sua esposa (Ellen) } \\
\text { e Nosferatu. }\end{array}$ \\
\hline Elenco principal & \begin{tabular}{|l} 
Max Schreck (Conde Orlok /Nosferatu), Gustav von \\
Wangenheim (Jonathan Hutter, empregado), Greta Schröeder \\
(Ellen Hutter, esposa), G. H. Schell (Harding Westrenka, \\
armador), Ruth Landshoff (Lucy Westrenka, irmã de Ellen), \\
Gustav Botz (Dr. Sievers), Alexander Granach (Knock \\
Renfield, agente imobiliário), John Gottowt (Professor \\
Bulwer, o Paracelsiano), Max Nemetz (capitão do barco), \\
Hardy von Francois (médico) e Wolfgang Heinz, Albert \\
Venohr, Heinrich Witte e Karl Etlinger (marinheiros) \\
\end{tabular} \\
\hline Contexto & $\begin{array}{l}\text { Histórico (período entre guerras mundiais), político } \\
\text { (República de Weimar), artístico (Escola Bauhaus) e } \\
\text { cinematográfico (1919-24) }\end{array}$ \\
\hline Influências & $\begin{array}{l}\text { Literatura fantástica e romance gótico, pintura romântica } \\
\text { alemã, expressionismo e romanticismo musical }\end{array}$ \\
\hline Restauro musical & $\begin{array}{l}\text { Reconstrução da partitura original de Hans Erdmann: } \\
\text { Berndt Heller (1984); interpretação: Rundfunk- } \\
\text { Sinfonieorchester Saarbrücken; direção: Berndt Heller; ano: } \\
\text { 2005/2006 }\end{array}$ \\
\hline
\end{tabular}


Table 1. Nosferatu, Eine Symphonie des Grauens

Metodologicamente, optou-se por um estudo de caso analítico-qualitativo (Stake, 2007) e descritivohermenêutico (Ashworth, 2000). Na análise estrutural da composição (Riemann, 1928) são utilizados outros métodos qualitativos, concentrando-se nas últimas diretrizes em musicologia sobre bandas sonoras de filmes (Tagg, 2012). O objeto de estudo centra-se na análise da música em articulação com os elementos visuais do filme (Casetti \& Di Chio, 2007), mergulhando numa análise da banda sonora, dos recursos estilístico-estéticos, dos contrastes de sonoridades, do desenho de motivos e frases musicais, em correlação com os elementos técnico-narrativos da imagem, contemplando a diversidade da instrumentação na partitura, as influências musicais diretas e correntes indiretas na sua criação e as referências ao estilo musical de compositores de renome na história da música.

\section{A Música de Erdmann em Nosferatu, Eine Symphonie des Grauens}

O compositor Hans Erdmann Timotheus Guckel (Breslau 1887-Berlin 1942) juntou-se à recémcriada companhia de produção alemã Prana-Film (1921, ao produtor Enrico Dieckmann e ao designer Albin Grau), assumindo a secção musical após uma carreira como músico de teatro (García Merino, 2016, p. 11). A sua permanência foi breve e ele compôs apenas a banda sonora deste filme, pois uma série de circunstâncias obrigou o estúdio a encerrar, tais como a acusação contra Murnau de violação dos direitos de autor do romance Drácula (Bram Stocker, 1897), a ação judicial imposta pela viúva do escritor e o facto de esta ter ganho, uma sentença desfavorável que ditou uma grande indemnização e a destruição de negativos e cópias do filme; tudo isto levou o estúdio a declarar falência. Apesar do incidente, Erdmann continuaria a sua carreira musical ligada ao cinema (García Merino, 2016, pp. 5-6), compondo para outros realizadores (Fritz Lang, Paul Wegener), como professor de música cinematográfica no Conservatório Klindworth-Scharwenka (Berlim), crítico musical e fundador da Gefima (uma sociedade que defendia os direitos de autor dos compositores de filmes).

Na sua ópera prima para Prana, Erdmann compõe uma obra sinfónica que corre harmoniosamente com a estética de Murnau. O filme conta a história de um empregado imobiliário (Jonathan Hutter) que viaja para os Cárpatos para comprar uma propriedade adquirida por um conde (Orlok) que é um vampiro (Nosferatu). Neste local acontecem-lhe coisas estranhas. Depois de fechar a venda, regressa à sua cidade e Nosferatu segue-o, viajando de barco para a sua nova residência escondido dentro de caixões com ratos aterrorizadores. Na viagem, a tripulação morre misteriosamente, e os ratos espalham-se como uma praga infeliz pela cidade. A mansão do vampiro fica perto da casa de Hutter e da sua esposa (Ellen). Uma forte atração fatal surge entre Nosferatu e Ellen.

Musicalmente, o filme está dividido em cinco atos que correspondem às diferentes partes da história, imitando a forma sinfónica com diferentes movimentos 1 . O subtítulo do filme apostila-o com a declaração "sinfonia do horror", sublinhando a influência da banda sonora na narrativa fílmica para provocar uma atmosfera emocional (Berriatúa, 1990b, p. 394). Para enfatizar a atmosfera do filme, Erdmann cria uma partitura influenciada pelo romantismo, mas que recorre a outros estilos (barroco, classicismo e impressionismo). Uma proposta que se distancia enormemente do expressionismo musical, estando mais próxima do período cinematográfico da produção.

O compositor opta por um programa sinfónico (Grout \& Palisca, 2002, p. 734) de grande formato, 
criado em torno de um tema descritivo, de carácter literário, estendendo uma mão ao classicismo musical. Abandonam-se as estruturas formais com uma exposição de motivos desenvolvidos a partir de uma ideia musical principal que serve de leitmotiv (Adorno, 2008, pp. 46, 94). Na sua criação, opta por uma orquestração sinfónica, com uma grande variedade de instrumentos para enriquecer o texto fílmico, associando as cenas a uma certa música, relacionando personagens a peças musicais específicas (leitmotiv wagneriano) e expressando certas situações, não só com a imagem mas também com a música e a utilização de certos instrumentos. Da mesma forma, o compositor integra silêncios musicais de forma sublime (Román, 2017, pp. 65-68) com um propósito poético.

A música de Erdmann integra-se à imagem de Murnau, paisagens musicais sob a forma de prelúdios perturbadores desvendam as identidades e a subconsciência das personagens (Neumeyer \& Buhler, 2001), a sua psicologia, sentimentos e comportamento, os vários locais (paisagens reais e subconscientes), atmosferas diferentes (sombras de iluminação expressionista), encenações conotadas (trajes de personagens, adereços) e as diferentes tonalidades de cor nas imagens com valor simbólico (sépia para a luz ao amanhecer, ocre ao anoitecer ou luz interior, azul escuro para a noite exterior), elementos que contribuem para criar um estado emocional no espectador.

Vários estilos musicais fluem através da imagem cinematográfica, a evolução e referência a peças de compositores de renome é percetível. O despertar do Hutter na estalagem é acompanhado pelo timbre dos sopros e violinos que com a sua expressividade ornamental identificam o amanhecer e os sons da natureza (canto dos pássaros, brisa do vento, água a murmurar), criando uma "paisagem sonora" (Schafer, 1994, p. 33) e recordando melodias bem conhecidas de Sarasate, Vivaldi ou Strauss.

Na cena da viagem de Hutter através da floresta ao anoitecer a caminho do castelo de Orlok, o movimento da carruagem tem aquele agitado carácter scherzo da música de Beethoven acompanhada pela imagem com um movimento acelerado ou undercranking (Konigsberg, 2004, p. 72) da carruagem. Na chegada de Hutter ao castelo, o tratamento melódico alude a Liszt e Chopin; enquanto a orquestração recorda as grandes sinfonias de Mahler, sendo sublime o instante da sua entrada na casa do vampiro, quando Orlok aparece.

Erdmann vai mais longe e dá poder aos instrumentos associando-os a elementos dos adereços, enriquecendo a imagem fílmica ao dotá-la de música descritiva; assim, a cena em que o relógio atinge a meia-noite (efeito acústico) é associada ao triângulo.

Na sua partitura podemos vislumbrar uma certa influência do leitmotiv wagneriano (Chion, 1997, p. 259), tal como a cena em que, após a meia-noite, Nosferatu entra na alcofa surpreendendo Hutter ao som de escalas de xilofones.

O romantismo permeia a cena final da morte dos amantes, Ellen (esposa de Jonathan) e Orlok (Nosferatu), tanto na imagem (cuidadosa direção artística e de palco nos adereços, detalhes dos móveis, figurinos) como na música (motivo de clarinete repetido com um dueto de violinos), para exprimir a imensa tristeza que ultrapassa aquele instante da morte por amor, uma menção à poética do romantismo.

A composição recorre a influências musicais do romantismo. Detetam-se pinceladas do barroco baixo contínuo sobre cordas, variações, modulações do tema principal e ornamentos para intensificar as emoções (Grout \& Palisca, 2002, pp. 490-491) - na cena da estalagem antes de Hutter iniciar a sua viagem para o castelo, com matizes de dança barroca.

Do mesmo modo, alusões ao classicismo - frases simétricas, frases equilibradas delimitadas por cadências, ideias combinando vento e corda, culminando num tutti orquestral - na cena noturna no navio, onde a tripulação espantada descobre ratos malcheirosos nos caixões do conde.

E vestígios de impressionismo - surtos sonoros de violinos, imitando relances em contínuos 
crescendos e diminuendos reminiscentes de Debussy e combinações instrumentais vivas - na cena do penhasco enquanto Ellen aguarda notícias do seu marido, tendo como única companhia os movimentos das ondas e a brisa do vento a enfatizar ainda mais a sua imensa solidão.

\section{Estudo Musical do Filme}

Para uma análise aprofundada, limitar-nos-emos, por razões espacio-temporais, a três fragmentos selecionados (edição 2008, Divisa Ediciones) pela sua relevância narrativa-estética e instrumental.

\section{Fragmento 1: Viagem de Hutter ao Castelo do Conde Orlok}

Um empregado imobiliário (Hutter) que se mudou para a Transilvânia para a compra de uma propriedade por um conde (Orlok) que é um vampiro (Nosferatu) está hospedado numa estalagem. Na terra dos Cárpatos descobre factos inusitados (00:17:57-00:25:26).

Musicalmente, é-nos apresentada uma melodia tonal descritiva, com um trabalho refinado de orquestração, instrumentação sinfónica (cordas, sopros e metais em pares, percussão e piano), desenvolvimento melódico e temático inspirado em períodos anteriores (barroco, classicismo, etc.). O início faz lembrar uma abertura ao estilo de Verdi, num diálogo entre cordas e sopros (solos de oboé, flauta e clarinete).

A cena começa com Hutter a acordar no quarto da estalagem. Os raios de luz do amanhecer entram pelas fendas da janela e envolvem a alcofa com uma aura luminosa - reforçada pela coloração sépia do fotograma -, enquanto se ouve o som do canto dos pássaros (em off). Abrindo a janela grande plano geral e profundidade de campo - , vê os cavalos a trotar livremente pelo campo, enquanto uma cordilheira de montanhas (aludindo aos Cárpatos) pode ser vislumbrada no horizonte. Uma paisagem bucólico-pastoral onde a música proporciona uma atmosfera idílica, acompanhando a imagem, onde os instrumentos cumprem com a paisagem uma "função referencial" (Jakobson, 1981, pp. 347-395).

Musicalmente, começa com um triângulo muito agudo (chamada de estilo militar), para despertar Hutter do seu profundo sono. O timbre dos sopros e dos violinos é identificado com sons da natureza (canto dos pássaros). Um recurso muito presente na história da música: El canto del rui señor de Sarasate, As quatro estações de Vivaldi ou a Sinfonia Alpina de Strauss.

Mais uma vez, o triângulo penetrante irrompe (repetição do tema inicial) e um ritardando leva a um novo motivo de clarinetes (Gráfico 1, Figura 1), apoiado por um obstinado ritmo com caixa e pandeireta (Gráfico 2, Figura 1). Coincidindo com a descoberta por Hutter de um livro sobre vampiros à beira da cama, as cordas envolvem a cena numa aura de mistério. Hutter atira então, a rir, o livro para o chão enquanto se prepara ao som de uma melodia jubilosa de clarinetes que reforça as suas ações e o seu humor. 

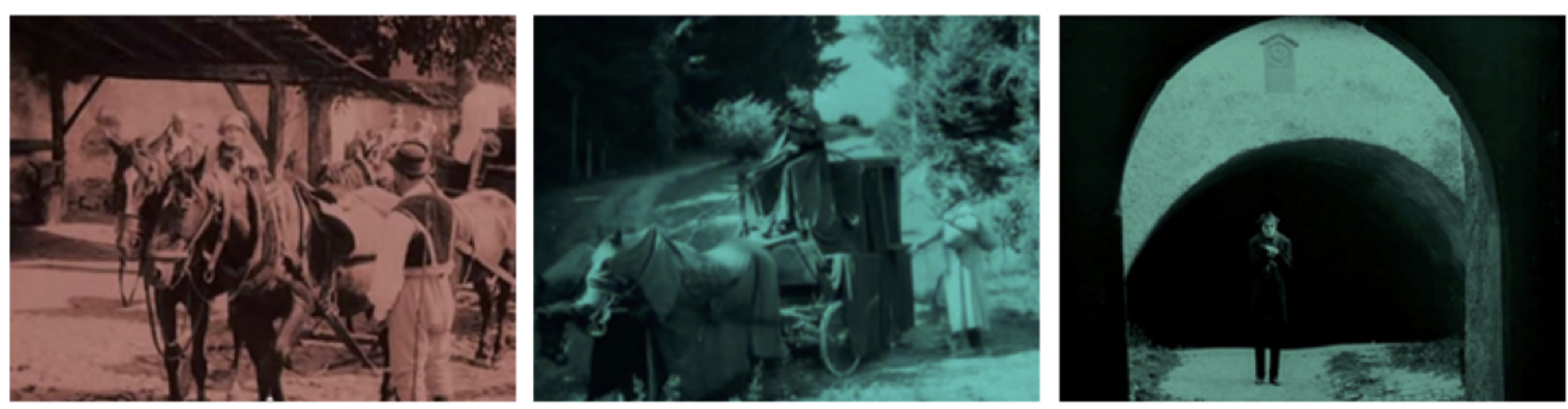

Gráfico 1

Gráfico 3
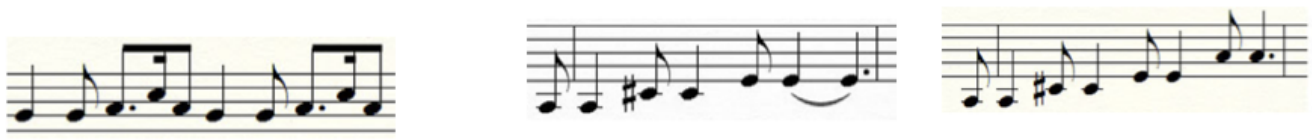

Análise musical

Gráfico 2

Gráfico 4

Gráfico 5
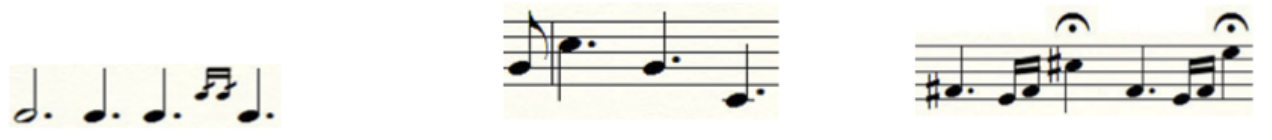

Instrumentos

Orquestra sinfónica: cordas (violinos, violas, violoncelos, contrabaixos), madeiras e metais a dois (dois oboés, duas flautas, dois clarinetes, dois fagotes, dois trompetes, duas trompas), percursão e piano

Fanfarra dialógica (pergunta-resposta), ostinatos rítmicos em percussão, carácter scherzo, progressões

Desenvolvimento ascendentes. Importância do silêncio, reexposição do tema principal, influências de Liszt ou Chopin, orquestração que recorda Mahler, interválica em oito notas

Composição

Música tonal. Influências do barroco, classicismo e romantismo

Figura 1. Viagem de Hutter ao castelo do conde Orlok Fonte. Nosferatu, Eine Symphonie des Grauens (Friedrich Murnau, 1922)

Numa montagem paralela, os cocheiros preparam a carruagem, o carácter lírico-expressivo das cordas atribuí credibilidade à viagem iminente. Musicalmente, começa com um carácter scherzo, tempo vivo e agitado, imitando o movimento acelerado (undercranking) da carruagem. Uma progressão ascendente, em crescendo nas cordas, leva-nos a um novo motivo. O piano (solista) propõe um tema em arpejo ascendente (oitavas), em diálogo com cordas e sopros, repetindo a mesma frase em forma de pergunta-resposta (Gráfico 3, Figura 1), reminiscente da sinfonia Heroica de Beethoven.

Enquanto na imagem a luz do pôr-do-sol é acentuada - com um fotograma em tons rosa a ocre -, musicalmente, uma mudança de motivo, uma chamada de clarinete (arpejo descendente) é repetida até quatro vezes (Gráfico 4, Figura 1). Há duas chamadas tutti (modo maior e modo menor), contribuindo para um maior dramatismo. Um ritardando prolongado mantém a tensão numa semicadência. Os cocheiros têm um mau pressentimento e de repente param a carruagem enquanto indicam a Hutter (plano-título): "paguem o que quiserem. Nós não continuamos". Por um segundo, há um silêncio sinistro, a sensação de vazio para enfatizar o momento perturbador. Um solo de 
violoncelo sobre um conjunto de cordas envolve a atmosfera inóspita da paisagem selvagem, como um parêntesis no scherzo porque, enquanto Hutter ri incredulamente, o tema principal regressa com um motor rítmico em cordas e uma melodia em sopros (clarinetes e flautas). A mesma progressão ascendente é repetida em cordas, culminando em tímpanos com um final de cordas de staccato (carácter monumental).

Esta paisagem sonora acompanha Hutter através de uma paisagem rochosa desolada. Viaja sozinho, caminhando, atravessando a ponte que o leva ao castelo de Orlok. É uma imagem com uma forte carga simbólica, pois a ponte pedonal separa o mundo dos vivos do dos mortos, e este limiar é reforçado pelo silêncio (efeito acústico) para enfatizar ainda mais a divisão de ambos os mundos (o real e o além). Perante a necessidade de expressar momentos sombrios e paisagens sinistras, Erdmann utiliza repetições e passagens que evoluem através do movimento conjunto, apresentando como novidade os cromatismos nos metais.

A imagem é acompanhada por toques do romantismo de Liszt e Chopin. Com uma mudança de melodia, carácter e atmosfera, iniciada no registo baixo e no tímpano (motor constante à maneira de uma marcha fúnebre). As trompetes desenvolvem um motivo (Gráfico 5, Figura 1), sobre um poderoso motor rítmico em cordas que se aproxima do clímax, criando um contraste que evoca Mahler, enfatizando a desolação de Hutter através do uso do silêncio (um efeito desgarrador e macabro).

Por trás de um plano com o título "assim que Hutter atravessa a ponte, é atingido por visões perturbadoras", a escuridão da noite impregna a floresta - escura de cor azul do fotograma —, e a grande torre do castelo aproxima-se imponente sobre a ponte. Uma nova carruagem preta aproxima-se rapidamente (undercranking) ao longo da estrada sinuosa para encontrar Hutter, animada por ondulações sonoras de violinos imitando flashes e redemoinhos, em contínuos crescendos e diminuendos, reminiscentes de Debussy. Uma progressão descendente em violinos aumenta a sua massa sonora para o registo baixo, acompanhando a descida da carruagem em direção a Hutter, culminando com uma nota de metais e um conjunto de tímpanos, enquanto um cocheiro enigmático é mostrado em primeiro plano, camuflando o seu rosto com um enorme chapéu e o colarinho alto do seu manto. Um intenso silêncio poético intensifica a intriga do encontro, ao assinalar Hutter, com um gesto de chicote com as mãos, para subir à carruagem. As progressões das cordas retomam ao ritmo vertiginoso da carruagem, as explosões de som refletem a atmosfera fantástica e onírica da música impressionista que envolve a viagem. Na névoa grossa da noite, a silhueta negra da carruagem é percebida e torna-se mais visível à medida que se aproxima, protegida pelo envolvimento musical (aumento da orquestração e do volume sonoro).

Com a sua chegada vem uma sucessão de sotaques tutti que passam a piano. O cocheiro que empunha o chicote ordena a Hutter que entre no castelo, e um grande plano da torre surge na imagem, acompanhado por um motivo de cordas no registo baixo, uma misteriosa melodia, auxiliada por intervenções súbitas do tímpano (atmosfera sinistra). Hutter vê a carruagem afastarse à pressa e os enormes portões do castelo abrem-se de par em par, com uma melodia expressiva com um tom de resignação. Um tilintar do tímpano anuncia a sua chegada, à medida que os portões se fecham magicamente. Orlok sai para saudar o seu convidado no meio de uma atmosfera sombria - de iluminação expressionista, a escuridão é acentuada pelo azul escuro do fotograma - que enfatiza a sua presença na noite, uma vez que o seu corpo emana uma enorme sombra de uma imagem fantasmagórica. À medida que se encontram, um motivo de violinos envolve a cena, enfatizando a perplexidade do momento, pois o enigmático cocheiro e o conde são uma e a mesma pessoa.

Depois de um novo intertítulo, "fizeste-me esperar tanto tempo. É quase meia-noite". Os criados estão a dormir e o anfitrião cede o lugar ao convidado. O clímax surge com um tilintar de pratos. À medida que entram no castelo, o oboé acompanha com uma melodia cada vez mais distante que perde energia, volume e intensidade, para concluir e fechar a cena em tutti. 


\section{Vista}

O movimento da ação decorre paralelamente à música, gerando tensão com frases longas. A relação entre acompanhamento e tema principal, bem como as relações entre famílias instrumentais, contrastes e efeitos tímbricos são a base da orquestração deste fragmento, que estabelece um precedente na composição para cinema (Figura 1).

\section{Fragmento 2: O Transe de Ellen}

Hutter hospeda-se no castelo de Orlok (Nosferatu), enquanto gere a compra de umas propriedades em Visborg. Depois da meia-noite, o conde (vampiro) irrompe pelo quarto do Hutter, com a intenção de o morder e sugar-lhe o sangue. Mas, ao longe, a sua esposa (Ellen) sente que algo terrível vai acontecer ao seu marido e entra em transe, acorda aos gritos a meio da noite e vagueia descalça pelos aposentos. Num estado de consciência alterado, entra numa conexão telepática com o vampiro que deixa o quarto do marido (00:33:11-00:37:58).

Uma cena de grande lirismo, onde, apesar do tonalismo predominante, os efeitos contrastantes reforçam o conteúdo. Após uma passagem de valor expressivo marcado em cordas (Fá maior), à semelhança de um pranto, surge o primeiro efeito com um forte cromatismo, funcionando a posteriori como o elemento principal (Gráfico 6, Figura 2). 

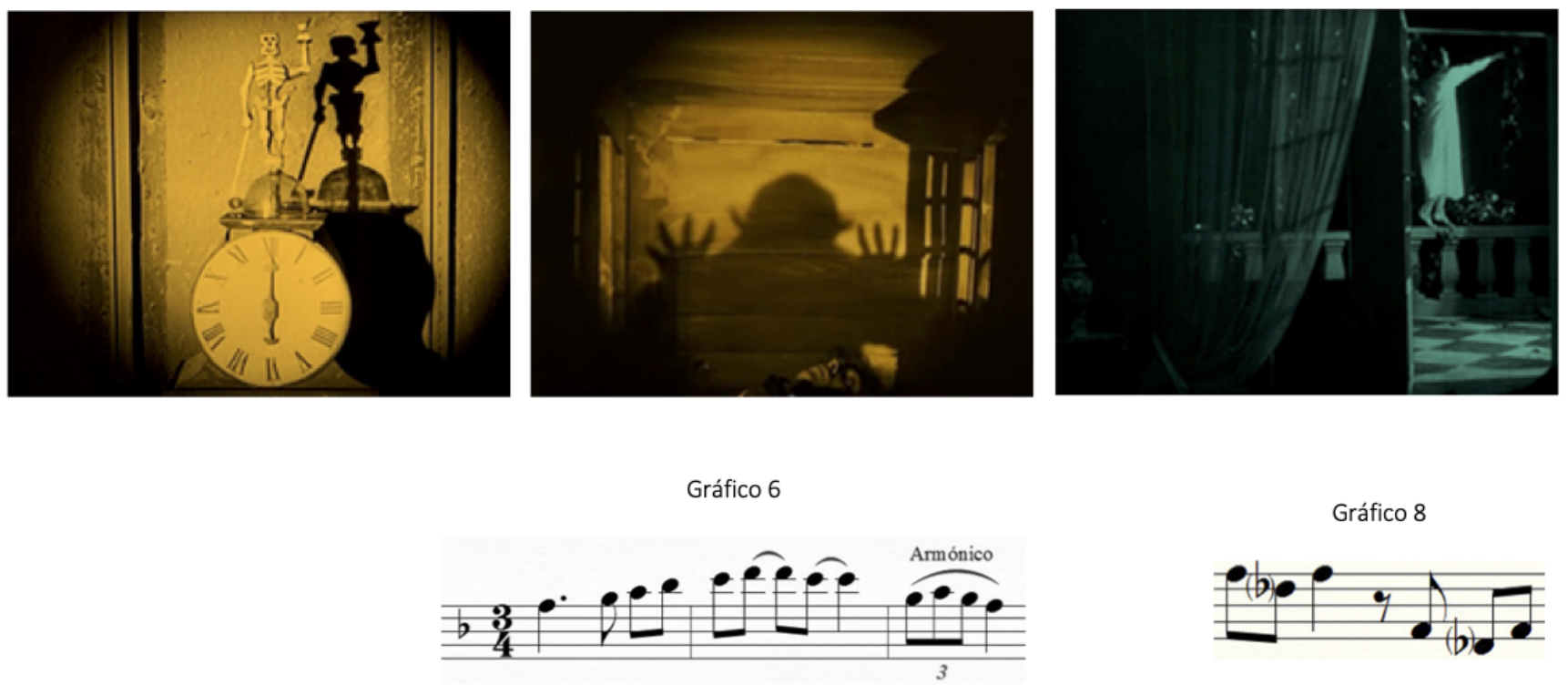

Gráfico 8

Análise musical

Gráfico 7

Gráfico 9

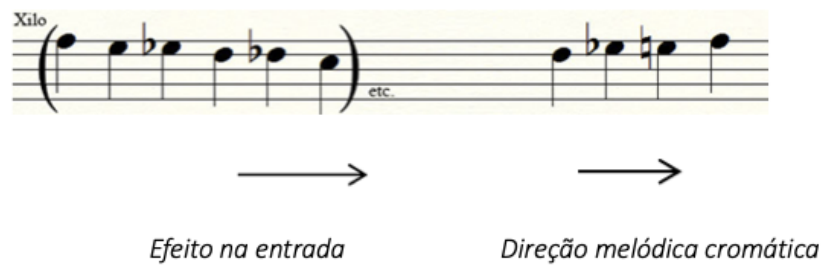

Instrumentos

Orquestra sinfónica: cordas (violinos, violas, violoncelos, contrabaixos), madeiras e metais a dois (dois oboés, duas flautas, dois clarinetes, dois fagotes, dois trompetes, duas trompas), percussão e piano

Desenvolvimento musical

Composição
Cromaticismo forte, frases longas com direção I, cadências não conclusivas, música descritiva, dissonâncias. Importância do silêncio, reexposição do tema principal, influências de Liszt ou Chopin, orquestração reminiscente de Mahler, interválica em oito notas

Música tonal. Influências do barroco, classicismo e romanticismo

Figura 2. O transe de Ellen Fonte. Nosferatu, Eine Symphonie des Grauens (Friedrich Murnau, 1922)

Na privacidade do seu quarto, Hutter beija o retrato da sua esposa no seu relógio de bolso, onde uma luz de vela - tom ocre sépia do fotograma - dá calor ao momento acompanhado por um motivo de violino, uma melodia amorosa enquanto recorda a sua amada, interrompido por uma escala descendente de corda e xilofone (Gráfico 7, Figura 2). Coincide com a exposição do livro de vampiros que Hutter tinha encontrado na estalagem e tira surpreendido da sua mala. Este estranho facto causa-lhe incerteza e é apoiado melodicamente com cromatismos que introduzem o tema (cadência não conclusiva), criando instabilidade e suspense (Gráfico 8, Figura 2).

Tem início uma base rítmica em contrabaixos, com sforzando repentinos nas cordas. Hutter olha secretamente para o livro, tentando descobrir o que está a acontecer, ao mesmo tempo que lê (plano-título, texto diegético, caligrafia gótica, tonalidade azul-esverdeada do fotograma), "à noite, o próprio Nosferatu fere a sua vítima com as garras e suga o seu sangue, a poção vital diabólica", 
vira a cabeça em direção à porta da sala, assustado e temeroso de ser descoberto. Continua-se a ler (plano-título) "certifica-te de que a sua sombra não te faz mal, como um pesadelo terrível".

Desenha-se uma linha melódica refinada e equilibrada, criando novos efeitos de cor instrumental (o cromatismo leva-nos à dominante), procurando a sua sonoridade plena para criar efeitos e atmosferas específicas. A melodia descritiva associa instrumentos com elementos decorativos do atrezzo. Assim, o aguçado triângulo é identificado com o toque das horas no relógio. Surge uma encenação cuidadosa de um grande plano de um relógio de mesa mecânico de bronze dourado com um mostrador redondo com numeração romana, decorado no topo por uma figura de esqueleto humano que toca um pequeno sino para marcar as horas. À meia-noite, ouvem-se exatamente 12 batidas de um triângulo em contraponto (cada batida um golpe) e uma escala decrescente de xilofone. Um momento de requintada plasticidade musical-fílmica porque, juntamente com a força expressiva da melodia, uma direção artística de objetos quotidianos é concebida com formas sombrias, iluminação expressionista, onde a sombra do relógio macabro gera uma imagem fantasmagórica animada.

O Hutter avança sigilosamente em direção à porta do quarto e quando a abre vê Nosferatu na escuridão. Um corpo hierático e definhado que personifica a fealdade, com uma enorme sombra refletida na parede que acentua ainda mais a escuridão do espaço. Musicalmente, a escala descendente de xilofones é enfatizada enquanto Hutter assustado fecha a porta. Um motivo de quatro notas é constantemente repetido nas cordas até a porta se abrir magicamente e Nosferatu se aproximar com uma marcha em forma de autómato, culminando num acorde dissonante (Gráfico 9, Figura 2).

O vampiro aproxima-se do quarto, passando pelo arco ogival da porta, acompanhado por uma melodia estática de xilofone e cordas, alternando com sons de flauta. O xilofone identifica Nosferatu, embora não seja visível na cena, devido ao seu carácter inexpressivo (instrumento sem ressonância) que contribui para descrever os movimentos lentos, robóticos, secos, incisivos e desumanos do vampiro. Um sforzando em tutti, acompanhado por um conjunto de tímpanos, reflete o medo de Hutter que, aterrorizado, cobre o seu rosto com os lençóis.

Quando Nosferatu fica imóvel no limiar do quarto, um silêncio intenso envolve a cena. Erdmann insiste na sua utilização para fins retóricos, para enfatizar o momento de desolação. Uma mudança de localização, por montagem paralela, leva-nos da Transilvânia para Visborg, onde Ellen dorme em sua cama. O piano e o registo baixo das cordas acompanham o seu sono, que pelos seus acordes inquietantes não parece agradável. A escuridão noturna - tom azul escuro do fotograma - invade o quarto, acorda, sonâmbula, e descalça, na ponta dos pés, sai para o terraço e começa a andar ao longo do corrimão da varanda. Ela está fora de si, à beira do abismo e desmaia. As melodias da flauta e do xilofone alertam o amigo de Hutter de que algo mau está a acontecer. Os instrumentos funcionam como um leitmotiv. O xilofone (representando Nosferatu) é ouvido ao fundo, presente na ação através da música, enquanto Ellen é a flauta (timbre inocente e quente).

A imagem leva-nos para a Transilvânia, para o quarto de Hutter. Tons dissonantes de flautins agitam a atmosfera e acompanham a enorme sombra do Nosferatu, que ganha vida e se lança lentamente sobre Hutter, encolhido no canto da cama, conferindo uma dimensão espectral à cena. O xilofone é reforçado pela combinação de elementos cromáticos e trompetes com surdina. O discurso melódico dirige-se para o clímax, destacando motivos de flauta sobre um colchão melódico em cordas graves, criando um motor que gera tensão como uma imagem dupla de sombras.

Ao mesmo tempo, Ellen, despertando de um pesadelo horrível, levanta-se da sua cama, com os braços estendidos, gritando o nome do seu marido. Um motivo de clarinete (instrumento que identifica Hutter) acompanha o seu pedido de ajuda. A sombra de Nosferatu, alertada pelo grito desesperado de Ellen, desvanece-se, diminuindo a densidade sonora. O vampiro vira-se e dirige o seu olhar (para fora do campo) para Ellen, enfatizando a existência de um laço entre eles. Nosferatu sai lentamente do quarto, acompanhado pelo xilofone, a porta fecha-se magicamente 
atrás dele. Nesse momento, à distância, Ellen cai rendida na cama, uma melodia de oboé e clarinete desvanece-se lentamente até ao seu descanso (Figura 2).

\section{Fragmento 3: Morte de Nosferatu e Ellen}

Orlok mudou-se para a sua nova mansão em frente à casa do casal Hutter. Ellen sucumbe à atração fatal de Nosferatu. Nas primeiras horas da manhã, o vampiro entra no seu quarto enquanto o seu marido vai à procura do médico (Bulwer). Nosferatu e Ellen, ávidos de desejo, deitam-se na cama. O amanhecer surpreende-os, os primeiros raios do amanhecer invadem a sala e acabam com a vida do vampiro, enquanto Ellen se abandona ao mesmo destino (01:25:37-01:33:20).

Cena sentimental em puro estilo do romantismo, musicalmente descritiva, com motores rítmicos constantes. O gongo é utilizado para realçar momentos dramáticos a fim de atrair a atenção (a "função factual" de Jakobson). É utilizado como um efeito associado ao movimento, culminando em convocações de cordas, criando um forte contraste com a atmosfera noturna acentuada na imagem pela tonalidade azul escura do fotograma (Gráfico 10, Figura 3).
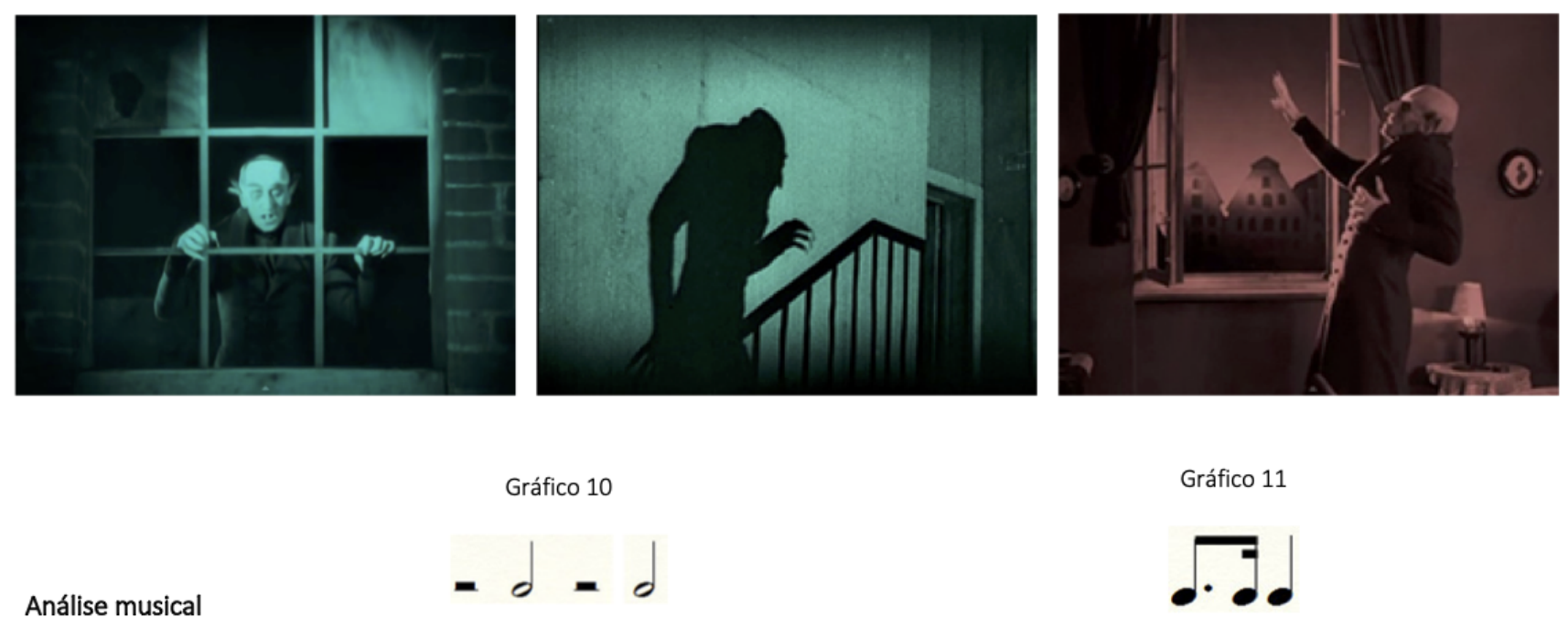

Gráfico 12

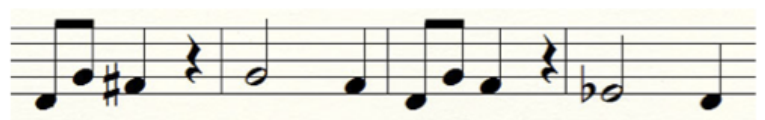

Instrumentos

Desenvolvimento musical

Composição
Orquestra sinfónica: cordas (violinos, violas, violoncelos, contrabaixos), madeiras e metais a dois (dois oboés, duas flautas, dois clarinetes, dois fagotes, dois trompetes, duas trompas), percussão e piano

Importância dos motores rítmicos (gong), diálogo entre cordas, motivos descendentes por semitons, importância tímpano. Corda como tema principal, estilo de procissão, importância dos metais graves, efeito frullato, motivo romântico

Música tonal. Influências do barroco, classicismo e romanticismo

Figura 3. Morte de Nosferatu e Elle Fonte. Nosferatu, Eine Symphonie des Grauens (Friedrich Murnau, 1922)

À noite, Nosferatu espera imóvel, descansando as suas mãos nas barras da janela em ruínas da sua nova casa. Imagem simbólica do prisioneiro privado da sua liberdade e do vampiro expectante à espera da sua nova presa. Musicalmente, a atrocidade materializa-se nas cordas graves (oitavas). 
Com o segundo golpe do gongo, Ellen acorda sobressaltada. Dois espaços físicos alternam-se - por montagem paralela - , o quarto do casal Hutter e a grande janela da mansão de Orlok, onde um terceiro espaço ocorre implicitamente, o psicológico, à medida que o vampiro e a Ellen comunicam por telepatia.

O registo grave e o sforzando mostram a falta de vigor de Nosferatu, enfatizando a sua lentidão, a mesma lentidão com que caminha. Enquanto Hutter, adormecido na poltrona junto à cama, vigia a sua esposa, uma mulher deprimida, resignada e impotente perante a situação. Ellen não consegue resistir à atração do vampiro, e, aflita enquanto olha para o seu marido, abre de vez em quando a janela do seu quarto, destapando o seu coração. Nosferatu vai ao seu encontro, altura em que a porta da mansão se abre repentina e magicamente e ela sai de casa, um instante reforçado por uma nota tocada em contrabaixo (aumento da tensão sonora). O som do gongo, como um apelo ritual, acompanha-o até à casa de uma Ellen atormentada, cujos pensamentos a mortificam, animada com música opressiva, floreados de cordas em diálogo e um motivo descendente de três notas, apoiado por um redobrar de tímpanos em crescendo que culmina com o gongo.

O seu marido acorda, assustado ao vê-la em tal estado de consternação, deita-a na cama e ela implora-lhe que chame Bulwer. Hutter sai a correr (motivo descendente de cordas), mas Ellen levanta-se, tendo enganado o seu marido para sair de casa. O tema é introduzido com uma convocação de tímpanos, repetida ao longo da secção (três notas descendo por semitons, adicionando tensão e aumentando a densidade sonora).

Nosferatu faz sentir a sua presença através da sua imensa sombra negra refletida na parede, fundida com a sombra das barras da escada, uma imagem metafórica do prisioneiro por amor. Ele entra no quarto de Ellen acompanhado pela força expressiva da música, a tensão cresce, alargando o registo, a densidade do som e a orquestração, unindo o vento metal em fortissimo, criando um contraste de cores com a instrumentação utilizada. Ellen já não suporta a angústia e cai exausta na cama (sforzando em fortissimo do tutti orquestral). Ela sabe que o seu fim está próximo. Um forte piano no tímpano acompanha o jogo de sombras das mãos do vampiro na camisa de noite branca de Ellen. A encenação faz lembrar o teatro de sombras chinesas, pois a sombra das mãos do vampiro em movimento projeta figuras animadas de animais voadores no peito da mulher, agarrando firmemente o seu coração, culminando o estado de ansiedade com um golpe de gongo.

Hutter acorda Bulwer (mesmo misterioso motivo de cordas). Na montagem paralela Nosferatu encontra-se sobre o corpo da Ellen deitada na cama. O aparecimento das diferentes personagens mostra musicalmente elementos de surpresa, uma mistura de simplicidade e complexidade. Os contrastes dos timbres fundem-se com certos padrões rítmicos e melodias sobrepostas e acentuadas. Erdmann, numa extraordinária tentativa de apoiar o desnudamento, emprega um elemento rítmico tipo procissão, definindo o carácter funerário nos metais graves (Gráfico 11, Figura 3).

Os primeiros raios do amanhecer aparecem no horizonte, penetrando subtilmente o quarto (um ponto realçado pela mudança de cor do fotograma de azul escuro para sépia). Duas vezes o canto do galo anuncia o amanhecer, parodiando o seu som com diferentes instrumentos (frullatono clarinete) e alerta não só Nosferatu, mas também Knock (o seu fiel servo e agente imobiliário). Este aviso leva-o de volta à realidade. Passou a noite com a sua amada, mas chega a luz do dia e morrerá com os primeiros raios de sol. Levanta-se lentamente da cama de Ellen, caminha imponente, a sua mão esquerda sobre o peito repousando no seu coração numa tentativa de preservar eternamente o seu amor. Ele vira o rosto para a janela e olha para fora (fora de campo) para o crepúsculo matinal à medida que o seu corpo se dissipa.

O sacrifício pelo amor, o medo e a resignação do momento refletem-se em frases longas, motivos e células rítmicas que se movem através de diferentes instrumentos, mostrando o desespero das personagens. Tematicamente, ideias claras e estruturas tonais definidas são desenvolvidas, levando a diferentes secções, acentuando a angústia (cadências não conclusivas), produzindo uma sensação 
de instabilidade e um redemoinho sem fim.

O tema final esboça uma melodia típica do romantismo, intensa, apaixonada, enquanto Knock grita (plano-título) "o mestre! O mestre!". O canto doce da flauta representa o amanhecer, empresta um ar bucólico à cena e o misterioso cromatismo acompanha o amanhecer. Os primeiros raios de sol inundam o corpo de Nosferatu, como lascas luminosas que acabam com a sua vida, enquanto uma escala descendente anuncia a sua descida ao inferno. A melodia melancólica das cordas, um lamento como um suspiro, é seguida por um triste motivo nos violinos, com resposta de violinos e violas, reafirmando a sua trágica morte (plano-título) “o mestre está morto" (Gráfico 12, Figura 3).

Após um desvanecer para o preto, a cena regressa ao quarto de Ellen onde, no seu último suspiro, acorda à procura do seu marido. O seu estado delirante é acompanhado por uma melodia melancólica de clarinete - simbólica do seu amor - enquanto Hutter a toma nos seus braços e ela morre. Sentimentos de profunda tristeza e imenso amor fundem-se num intenso motivo melódico, repetido em dueto de violinos (instrumento romântico por excelência).

A orquestração desenha o jogo colorido de luz e sombra presente, explorando os limites instrumentais nos extremos graves (timbres mais escuros e sonoridade menos intensa) e agudos (rangidos), procurando novos efeitos (cor instrumental e atmosfera). A cena fecha-se rompendo com o drama vivido, atingindo uma cadência tonal que liberta toda a tensão acumulada, enquanto a profecia é mostrada em imagem (plano de título, texto diegético, caligrafia gótica e coloração azulesverdeada do fotograma), "e, de acordo com a verdade, documenta-se o milagre: na mesma hora a grande mortalidade cessou e, como antes, os raios solares vitoriosos cheios de vida dissiparam as sombras da ave de mau agouro". Uma imagem geral do castelo do conde Orlok na Transilvânia encerra o filme com um desvanecimento para o preto (Figura 3).

\section{Notas Finais}

Nosferatu, Eine Symphonie des Grauens de Murnau é considerado uma obra-prima do género de horror (vampírico) do cinema expressionista alemão. As contribuições significativas para a mesma têm proliferado a partir de diferentes abordagens disciplinares, mas quando é abordada do ponto de vista musicológico, os estudos são escassos, uma circunstância que se pode dever à perda da partitura original de Hans Erdmann. Ao longo do tempo, a imagem foi restaurada várias vezes com diferentes tonalidades de cor (Patalas, Berriatúa, etc.) e o mesmo aconteceu com a partitura (Heller, Anderson e Kessler, Müller e Plebuch). O filme restaurado por Friedrich Wilhelm Murnau Stiftung (2005/2006) tem uma partitura original reconstruída por Heller (1984).

O filme baseia-se nas referências culturais da época, pintura romântica e expressionista, literatura fantástica e romances góticos, kammerspiel e música romântica. Uma composição que mostra a evolução do romantismo musical e a sua referência a peças de compositores de renome. Erdmann opta por uma sinfonia programática em grande escala, criada em torno de um tema descritivo, recorrendo a outros estilos musicais.

A partitura está estruturada em cinco atos correspondentes às partes da história de Nosferatu, imitando a forma sinfónica com diferentes movimentos. Uma criação romântica intensa, com música tonal com uma certa influência do barroco, classicismo e impressionismo que brinca com o estado emocional criando atmosferas, adaptando-se a cada uma das cenas e respeitando o mais pequeno detalhe graças ao domínio de cromatismos e dissonâncias.

Erdmann opta por uma instrumentação sinfónica que enobrece o texto fílmico associando personagens com instrumentos, as suas ações e emoções com melodias e as cenas com uma certa música. É influenciado pelo leitmotiv wagneriano que dá ao filme uma densidade sonora e recorre majestosamente a silêncios musicais com um propósito poético. Desenvolve, ainda, magistralmente formas musicais como a fanfarra e a marcha fúnebre, sem perder a originalidade, combinando todo 
o tipo de técnicas, orquestração e estilos. O autor emprega habilmente os diálogos entre diferentes famílias instrumentais e atribuí um papel relevante à percussão e aos seus múltiplos efeitos.

No tratamento melódico é influenciado por Liszt e Chopin; na orquestração recorda as grandes sinfonias de Mahler; domina o impacto dramático e a rica orquestração de Stravinsky; cita memoravelmente os scherzos de Beethoven; deixa a sua marca nas composições de Debussy, com surtos sonoros de violinos, imitando relances em contínuos crescendos e diminuendos; liga sabiamente a técnica wagneriana leitmotiv, guiando a melodia em diferentes direções e criando momentos melódicos únicos e irrepetíveis; revive acompanhamentos marciais no estilo de Verdi; e evoca subtilmente melodias de Vivaldi e Strauss.

O ensemble instrumental apresenta as diferentes personagens que compõem o triângulo amoroso da história, as ações que realizam, os sentimentos que os atormentam e os desejos inconfessáveis que sentem; Nosferatu é representado pelo xilofone, Ellen pela flauta e Jonathan pelo clarinete. Alguns instrumentos são também utilizados para descrever emoções que emergem das diferentes paisagens da história fílmica: o som marcante do gongo, como um apelo solene ao encontro amoroso de Ellen e Nosferatu; o frullato no clarinete, imitando o canto do galo ao amanhecer; o som agudo do triângulo como uma revelação para acordar Hutter; ou os violinos, aludindo ao trio das aves. A música de Hans Erdmann integra-se harmoniosamente com a imagem de Friedrich Murnau, uma banda sonora em perfeita simbiose com a história do filme.

\section{Notas biográficas}

Anna Amorós-Pons, professora de comunicação audiovisual e publicidade na Universidade de Vigo, é doutorada em ciências da comunicação pela Universitat Autònoma de Barcelona, argumentista e realizadora de documentários. É co-coordenadora da master class AuGAL, diretora de Obradoiros de Cine. Periodista de Honra (Asociación de Prensa de Vigo) e Prémio de Boas Práticas em Comunicação Não Sexista (Associació Dones Periodistes de Catalunya).

ORCID: https://orcid.org/0000-0002-2233-0102

\section{Email: amoros@uvigo.es}

Morada: Facultade de Ciencias Sociais e da Comunicación, Campus A Xunqueira, CP: 36005, Pontevedra, España

Nuria Gómez-Otero é licenciada em publicidade e relações públicas pela Universidade de Vigo, tem licenciatura profissional em percussão pelo Conservatório Profissional de Redondela e é doutorada em publicidade, relações públicas e comunicação audiovisual. É compositora, intérprete musical e professora de música desde 2004, de piano, saxofone, música em movimento, percussão e solfejo.

ORCID: https://orcid.org/0000-0003-4046-3598

Email: nuriagomezotero@live.com

Morada: Centro Musical LIRA-San Miguel de Oia, Vigo, Espanha.

\section{Notas}

1. As sinfonias têm normalmente quatro movimentos, mas há casos com cinco (segunda, quinta e sétima sinfonias de Mahler; Fantastiquede Berlioz, etc.). 


\section{Referências}

Adorno, T. W. (2008). Ensayo sobre Wagner. Akal.

Altman, R. (2007). Silent film sound. Columbia University Press.

Amorós, A., \& Gómez, N. (2017). La música de Rainer Viertlböck en la versión restaurada del film Daskabinett des Doktor Caligari, de Robert Wiene (1919). Cuadernos de Música, Artes Visuales y Artes Escénicas, 12(2), 321-343. https://doi.org/10.11144/Javeriana.mavae12-2.mrvv

Amorós, A., \& Gómez, N. (2018). The German expressionist film The Golem (1920): Study of the music soundtrack by Aljoscha Zimmermann. L'Atalante. Revista de Estudios Cinematográficos, 26, 181-198.

Anderson, G. B. (1988). Music for silent films, 1894-1929: A guide. Library of Congress.

Ashworth, P. D. (2000). Qualitative research methods. Estudio Pedagógico, 26, 91-106. http://revistas.uach.cl/pdf/estped/n26/art07.pdf

Berriatúa, L. (1990a). Apuntes sobre las técnicas de dirección cinematográfica de F. W. Murnau. Filmoteca Regional de Murcia.

Berriatúa, L. (1990b). Los proverbios chinos de F. W. Murnau (Vol. II). Filmoteca Española.

Berriatúa, L. (2001). Conocer los materiales para restaurar películas. Biblioteca Virtual Miguel de Cervantes Instituto de la Cinematografía y Artes Audiovisuales Filmoteca Española.

Berriatúa, L. (2009). Nosferatu: Un film erótico-ocultista-espiritista-metafísico. Divisa Red.

Berriatúa, L., \& Pérez, M. Á. (1981). Etudes pour une reconstitution du Nosferatu de F. W. Murnau. Les Cahiers de la Cinémathèque, (32), 61-74.

Bouvier, M., \& Leutrat, J.-L. (1981). Nosferatu. Cahiers du Cinéma Gallimard.

Casetti, F., \& Di Chio, F. (2007). Cómo analizar un film. Paidós.

Chion, M. (1982). Leson au cinema. Cahiers du Cinéma.

Chion, M. (1993). La audiovisión: Introducción a un análisis conjunto de la imagen y el sonido (A. L. Ruiz, Trad.). Paidós. (Trabalho original publicado em 1990)

Chion, M. (1997). La música en el cine (M. Frau, Trad.). Paidós. (Trabalho original publicado em 1995)

Colón, C., Infante, F., \& Lombardo, M. (1997). Historia y teoría de la música en el cine: Presencias afectivas. Alfar.

Deutsche Kinemathek. (2003).

Retrospektive, filmografie. https://www.deutsche-

kinemathek.de/retrospektive/retrospektive-2003/filme/15

Eisner, L. H. (1964). F. W. Murnau. Le Terrain Vague.

Eisner, L. H (1996). La pantalla de moniaca. Las influencias de Max Reinhardt y del expresionismo 
(I. Bonet, Trad.). Cátedra. (Trabalho original publicado em 1955)

Fraile, T. (2007). El elemento musical en el cine: Un modelo de análisis. In J. Marzal \& F. J. Gómez (Eds.), Metodologías de análisis del film (pp. 527-538). Edipo.

García Merino, J. (2016). Nosferatu y la consolidaciónde la música de cine. In Programa Nosferatu, eine symphonie des grauens (pp. 3-11). Junta de Castilla y León. Consejería de Cultura y Turismo Fundación Siglo para el Turismo y las Artes de Castilla y León. https://www.oscyl.com/assets/oscylprograma-nosferatu.pdf

Gillian Anderson. (s.d.). Nosferatu.

http://www.gilliananderson.it/index.php?option=com_k2\&view=item\&layout=item\&id=22\&Itemid $=29$

González, J. L. (2008). Vampiros en el cine mudo. 'Nosferatu' (1922) de Murnau. Revista Cine y Letras.

http://www.cineyletras.es/Clasicos-y-DVD/vampiros-en-el-cine-mudo-nosferatu-1922-demurnau.html

González Hevia, L. (2012). La sombra del vampiro. Su presencia en el 7o arte. Cultiva Libros.

Grout, D. J., \& Palisca, C. V. (2002). Historia de la música occidental. Alianza Música.

Hayward, P. (2009). Terror tracks: Music, sound and horror cinema (genre, music \& sound). Equinox Publishing.

Heller, B. (1984). Restauración. In Nosferatu. La película. Divisa Home Video.

Jakobson, R. (1981). Ensayos de lingüística general. Seix Barral.

Jameux, C. (1965). Murnau. Editions Universitaires.

Konigsberg, I. (2004). Diccionario técnico akal de cine. Akal.

Kracauer, S. (1985). De Caligari a Hitler. Una historia psicológica del cine alemán (H. Grossi, Trad.). Paidós. (Trabalho original publicado em 1947)

Lack, R. (1999). La música en el cine (H. Bevia \& A. Resines, Trads.). Cátedra.

Lerner, N. (2009). Music in the horror film: Listening to fear. Taylor \& Francis.

Lluis i Falcó, J. (1995). Paràmetres per a una anàlisi de la banda sonora musical cinematográfica.

D'Art. Revista del Departament d'Història de l'Art, (21), 169-186.

Marks, M. M. (1997), Music and the silent film: Contexts and case studies, 1895-1924. Oxford University Press.

Müller, J., \& Plebuch, T. (2013). Toward a prehistory of film music: Hans Erdmann's score for Nosferatu and the idea of modular form. Journal of Film Music, 6(1), 31-48.

https://doi.org/10.1558/jfm.v6i1.31

Murnau, F. G. (Diretor). (1922). Nosferatu, Eine Symphonie des Grauens [Filme]. Prana-Film.

Navarro Arriola, H. y S. (2005). Música de cine: Historia y coleccionismo de bandas sonoras.

Ediciones Internacionales Universitarias. 
Neumeyer, D., \& Buhler, J. (2001). Analytical and interpretive approaches to film music (I):

Analysing the music. In K. Donnelly (Ed.), Film music. Critical approaches (pp. 16-38). Edinburgh University Press.

Nieto, J. (2003). Música para la imagen: La influencia secreta. SGAE.

Olarte, M. (2004). La música de cine. De los temas expresivos del cine mudo al sinfonismo americano. En J. M. García (Ed.), La música moderna y contemporánea a través de los escritos de sus protagonistas (pp. 109-126). Doble J. http://hdl.handle.net/10366/76672

Olarte, M. (2008). Utilización de la música clásica como música preexistente cinematográfica. In J. M. García \& E. Arteaga (Eds.), En torno a Mozart. Reflexiones desde la universidad (pp. 71-84). Ediciones Universidad de Salamanca. http://hdl.handle.net/10366/76649

Patalas, E. (2002). Les restaurations du 'Nosferatu' de Murnau. Cinématèque, 21, 117-134.

Peña Sevilla, J. De la. (2000). Una aproximación iconográfica del cine de vampiros. Imafronte, (15), 237-254.

Riemann, H. (1928). Teoríageneral de la música. Labor.

Román, A. (2017). Análisis musivisual. Guía deaudición y estudio de la música cinematográfica. Visión Libros.

Rubio, S. (2005). Nosferatu y Murnau: Las influencias pictóricas. Anales de Historia del Arte, 15, 297-325.

Sánchez-Biosca, V. (1985). Del otro lado: La metáfora. Modelos de representación en el cine de Weimar. Instituto de Cine y Radiotelevisión/Hiperión.

Sánchez-Biosca, V. (1990). Sombras de Weimar, contribución a la historia del cine alemán 1918-1933. Verdoux.

Schafer, M. (1994). The soundscape: Our sonic environment and the tuning of the world. Destinity Books.

Stake, R. E. (2007). Investigación con estudio de casos. Morata.

Tagg, P. (2012). Music's meanings. A modern musicology for non-musos. The Mass Media Music Scholars Press.

Tieber, C., \& Windisch, A. (2014). The sounds of silent films: New perspectives on history, theory, and practice. Palgrave Macmillan.

Tone, P. G. (1976). Friedrich Wilhelm Murnau. La Nuova Italia.

Torelló, J. (2015). La música en las maneras de representación cinematográfica. Laboratori de Mitjans Interactius.

Valls, M., \& Padrol, J. (1986). Música y cine. Salvat.

Este trabalho está licenciado com uma Licença Creative Commons - Atribuição 4.0 Internacional. 